Article

\title{
Analysing Consumer Preferences, Characteristics, and Behaviour to Identify Energy-Efficient Consumers
}

\author{
Janez Dolšak *, Nevenka Hrovatin and Jelena Zorić \\ School of Economics and Business, University of Ljubljana, 1000 Ljubljana, Slovenia; \\ nevenka.hrovatin@ef.uni-lj.si (N.H.); jelena.zoric@ef.uni-lj.si (J.Z.) \\ * Correspondence: janez.dolsak@ef.uni-lj.si; Tel.: +386-(0)1-5892-550
}

Received: 3 November 2020; Accepted: 23 November 2020; Published: 25 November 2020

\begin{abstract}
This paper investigates preference heterogeneity among Slovenian energy consumers and attempts to ascertain how different consumer groups value various attributes of energy products and services. More specifically, it aims to establish whether a consumer segment can be identified that shows a preference for additional energy services-in particular services, associated with energy-efficient and green behaviour. A latent class analysis is employed to classify consumers on the basis of their preferences for energy services. Additionally, information about their attitudes and behaviour toward green energy and energy efficiency, energy consumption, and usage of energy services together with socio-economic characteristics is used in the latent class regression to explain differences between latent consumer classes. Three classes are identified: the largest class of regular consumers, energy-efficient consumers, and dissatisfied consumers. In contrast to regular and dissatisfied consumers, energy-efficient consumers show a significantly higher interest in additional services, energy efficiency, and green energy. In line with the found heterogeneity of consumer preferences, suppliers should customise marketing strategies to meet the needs of specific segments. Energy policymakers also need to pay more attention to consumer heterogeneity and behavioural changes to increase the effectiveness of energy efficiency policies.
\end{abstract}

Keywords: energy efficiency; residential energy market; consumer preference heterogeneity

\section{Introduction}

Energy markets are undergoing a major transition, mainly driven by new market strategies aimed at increased consumer engagement and climate change policies [1]. The transition, starting with the deregulation of energy markets, has not only increased market competition but has also enriched the suppliers' offers with a variety of additional services, including green energy and energy-efficient technologies [2,3]. Energy suppliers expanded their portfolio with additional products and services, such as a combined (multi-fuel) energy supply, strengthened communication with consumers, sales, and installations of energy-efficient electrical appliances, energy-efficiency consultations, and provision of other energy-related services in order to meet the expectations of most consumer segments. Their main goal is to establish effective relationships with consumers with the intention of building long-term relationships. These trends may eventually change the perception of energy suppliers [4]. The product and service differentiation can be seen as one of the main results of energy market deregulation since this also indirectly enhances consumers' market activities. This is particularly important when promoting green energy and energy efficiency (EE) with the current climate change policies [5]. Consequently, consumers are free to choose an energy supplier, as well as to choose from various energy products on the basis of not only the price but also several other factors impacting consumer preferences for a supplier offer [6]. 
Since consumer preferences are becoming more diverse with expanded supplier offers, it is important to understand how consumers make decisions about energy products and services when those decisions necessitate trade-offs between various benefits and costs $[7,8]$. Understanding consumer preferences and identifying their potential heterogeneity when valuing various products and services together with their attributes is crucial for effectively addressing consumers' needs. Energy suppliers are therefore forced to transform into active, consumer-oriented utilities with an emphasis on the integration of energy services, while simultaneously promoting environmental sustainability [9]. The residential sector, which accounts for a considerable share of energy use, represents an important potential for energy savings, especially because of the persistence of an energy efficiency gap [10]. Enriching the knowledge on household energy preferences, behaviours, and attitudes is thus crucial to enhance the effectiveness of the energy efficiency policies, which should play a central role in the European Union (EU) together with green energy and climate change goals.

It is expected that the consumer base will become even more heterogeneous, and so knowledge about different consumer segments is crucial to develop an adequate approach towards consumers [11]. Especially in the energy sector, the primary goal for utilities is to understand which energy services and which attributes consumers prefer. Ideally, the energy market should focus on the development and the awareness of efficient energy use and the use of green energy, which may create, together with the efficient relationship management, a competitive advantage strategy for any supplier [12]. As consumer preferences, attitudes, and energy consumption along with consumer heterogeneity may be country-specific, they call for country studies.

The main objective of our study is to investigate preference heterogeneity among Slovenian consumers and to establish how different consumer groups value different attributes of energy products and services. Identification of consumer groups based on their preferences related to energy offers may serve as important information in developing new business strategies and improving energy policies. Our hypotheses are:

Hypothesis 1 (H1). Consumer preferences for energy services are heterogeneous, so more than one consumer segment could be identified based on the range of preferences for energy services.

Hypothesis 2 (H2). A consumer segment could be identified that shows pro-energy-efficient behaviour and higher preferences and attitudes towards energy efficiency and green energy.

Several studies have been trying to explain the influence of behavioural aspects on energy consumption and consequently, on energy-saving behaviour $[7,13,14]$. While these authors mainly focused on the factors that influence residential energy consumption, our paper enriches the knowledge on the heterogeneity of consumer groups by taking into account their preferences for energy services. To the best of our knowledge, there is no comparable study that examines consumer heterogeneity and segmentation based on consumer preferences along with their attitudinal, behavioural, and socio-economic characteristics.

The paper is organised into five sections as follows. Section 2 first reviews the literature on the determinants of consumer preferences in general and specifically in the energy markets, while also addressing their heterogeneity. In Section 3, the data and research methods for conducting the empirical analysis are described. Section 4 presents the empirical results of the latent class analysis and the latent class regression, which identify differences between latent consumer classes. The last section contains a discussion of the results and suggests managerial and policy implications for energy suppliers and energy policymakers, respectively. 


\section{Theoretical Background}

\subsection{Slovenian Residential Electricity Market as a Research Setting}

Slovenia is an interesting research setting since it is a young European Union member state whose energy markets have become increasingly active in recent years [15]. Competitive pressure came with the entry of new electricity suppliers after 2008 who introduced business strategies that focus on consumers and product differentiation [16]. In 2015, the retail electricity market in Slovenia faced stiff competition from 13 electricity suppliers to residential consumers [17]. The strengthened competition caused a decrease in the contestable part of the final electricity price (i.e., the energy component) [17]. As a result, the savings from switching have been gradually shrinking. The potential annual benefit from switching suppliers was between EUR 43 and EUR 85 in 2015, almost half compared to 2011-2014 when it peaked around EUR 110 [17]. As a result, rivalry in the electricity market has gradually shifted from price competition to other forms of competition based on additional offers of a supplier. Suppliers are, therefore, extremely interested in identifying heterogeneous consumer segments' needs to adequately tailor their package offers.

In line with the EU Energy Efficiency Directive (EED) [18], Slovenia as an EU member state is also obliged to establish its energy efficiency obligation scheme, which should determine both the level of energy savings by 2020, and the parties obliged to achieve these savings. In accordance with the EED, the savings under the national energy efficiency obligation scheme in the period 2014-2020 have to represent at least $1.5 \%$ of annual energy sales to final consumers in the previous year. Slovenia pursues a combined policy in which half of these obligations will be achieved by the public Eco Fund programmes, financed by levies on energy. Energy suppliers are motivated to fulfil these obligations, because, firstly, in the case of a failure, a certain proportion of their revenue must be paid to the public environmental fund, which could be perceived as a penalty. Secondly, the obligation provides the opportunity for expanding their regular offer by providing energy efficiency consultation, services, and the installation of energy-efficient appliances and technologies. Recently, Slovenia prepared the Integrated National Energy and Climate Plan, which contains new energy-climate policy targets for the period until 2030 [15]. According to the new targets, Slovenia aims to improve energy efficiency by at least 35\% compared to the 2007 reference values. A significant increase in the targets requires significant energy efficiency improvements, for which the involvement of all energy market participants is needed [15].

\subsection{Consumer Preference Heterogeneity}

The transition of energy markets, including recent advances in the demand-side management, has rekindled interest in consumer behaviour [19] and how this knowledge can be fed into more effective energy policies [20]. On the other hand, this knowledge is crucial for energy suppliers to maintain their market shares, especially in terms of the awareness of the increasing importance of differentiation and, above all, integration of energy services [21]. The latter encompasses the offer of various energy fuels for the residential sector, as well as the offer of energy services focused on the efficient use of energy, the reduction of energy-related costs, energy conservation, and environmentally friendly use. A comprehensive offer of energy services provides opportunities for the sustainable development of business strategies for energy markets since it takes into account both an increased consumer engagement and climate change policies. The energy supply is becoming a heterogeneous service that provides numerous energy products from various energy sources. However, energy is an intangible and a low-involvement product, while consumer decisions are often based on other attributes besides price. Identifying the diversity of consumer preferences is essential for developing effective market strategies. Knowing the characteristics of each consumer segment can help develop product and service differentiation that meets most consumer needs [22]. Through a better understanding of consumers, the gap between consumer preferences and a product portfolio can be eventually closed [9].

Consumer preferences serve as standards for an assessment of service, and so importantly determine the level of consumer satisfaction [23]. The literature reveals that consumer satisfaction can 
be successfully managed by improving so-called 'supplier's brand associations,' namely, the perceived technical service quality and service process quality, a perception of value-added services, environmental and social commitment of the supplier, brand trust, and price perceptions [4]. Büscher and Sumpf [24] argue that previous research has underestimated the importance of the social mechanism of trust and confidence for consumers as technical innovation and institutional change cannot solely enhance consumer's participation. Building strong associations with suppliers relies on the attributes and benefits of the supplier's products and services [25].

Beside brand reputation, consumer preferences may be importantly influenced by the supplier's environmental awareness, which is exhibited by providing energy from renewable sources and promoting energy efficiency. Moreover, emerging carbon mitigation measures are suggesting energy suppliers also promote their care for low carbon footprints [26]. Since the community across Europe, and in other developed countries, is becoming more sensitive to environmental issues, there is a growing public concern for environmental protection [4], which consequently and importantly impacts consumer preferences. Particularly important energy service attributes have to be considered with great care. Although most consumers support green energy, they often hesitate to pay for it because of a lack of transparency about their energy supplier's environmental performance [5]. Their objective that their money does not support unsustainable energy sources has to be satisfied in order to reap their "environmental" trust. Energy suppliers are therefore trying to improve their image as environmentally aware suppliers, either through their existing marketing strategies or through the implementation of new marketing strategies, with an emphasis on energy efficiency and by offering green energy with a particularly environmentally friendly public image. Accounting for multiple energy service attributes enables jointly testing their relevance and also their importance for further examination of consumer behaviour.

Consumer preferences related to energy efficiency activities are primarily affected by their behaviour toward energy use, their attitudes and habits, their environmental values, and knowledge [27]. Energy-efficient behaviour reflects not only an environmentally friendly attitude but also the willingness to reduce costs, both impacting energy consumption. Research on energy-efficient behaviour has identified various non-technical determinants of energy consumption, which may be explained by consumers' socio-economic and socio-demographic characteristics, as well as their environmental awareness [10,14,28-30].

Two recent studies by Belaï [30] and Belaïd et al. [14], for example, emphasise the impact of behavioural factors in residential energy consumption. Moreover, social interactions and beliefs about other people's willingness to reduce electricity consumption are potential triggers for one's energy-saving behaviour. Further, a high degree of social integration, e.g., in social networks, is also positively related with the acceptance of energy-saving behaviour [29]. Ek and Söderholm [31] concluded that among all possible triggers of energy-saving behaviour, price incentives, information, and environmental moral concerns might be the most effective ones. A review on behavioural-based energy efficiency programs conducted by Dougherty and Van de Grift [32] suggests that future studies must evaluate their impact of how these programs generate energy savings, as well as explore the most effective ways to integrate them into an existing service portfolio. However, according to Blum [33], additional benefits from improved energy efficiency do not always outweigh the additional costs. Thus, several market failures and barriers may importantly influence public acceptance of these programs, where research in social science may help find ways to overcome them [34].

When analysing preferences for energy-saving behaviour, researchers were also interested in the heterogeneity of consumers. Recently, Hille et al. [22] found heterogeneity in preferences for participation in electricity-saving programs defined by several attributes (i.e., goal setting, tailored feedback provision, and reward and penalty schemes) using a latent class approach. Consumer segments could then be categorised in terms of their psychographic and socio-demographic characteristics in order to effectively tailor marketing and communication programs. Consumer preference heterogeneity was also found in the study of consumer attitudes to various attributes of electrical appliances, including their energy-saving 
and emission-reducing features. In a recent study, Sung-Yoon et al. [35] found a high heterogeneity of consumer preferences for all characteristics of an electrical appliance (i.e., rice cooker) with high importance of the price attribute. Similarly, heterogeneity was revealed in consumer preferences for the heating system. Although consumers gave the highest priority to the heating system costs, followed by the label indicating carbon dioxide emissions, three clusters were detected among Italian consumers in relation to these attributes [36], which requires a combination of policies to achieve the largest reductions of greenhouse gas emissions in the heating sector.

A common conclusion in the literature on consumer preferences is that preferences are heterogeneous and so a priori understanding heterogeneity of consumer preferences can improve consumer satisfaction through customised services for individual consumers [37]. One important indicator of successful identification of consumer heterogeneity for a particular service is the supplier-switching rate, which is, for example, in banking and telecommunications twice as high as in the energy market [38]. Studies by Yang et al. [7] and Hartmann and Apaolaza Ibáñez [6] confirm that consumer preferences for energy services are heterogeneous, where failing to understand their diversity may steer energy suppliers to develop ineffective market strategies. Ek and Söderholm [31] conducted a study on the switching behaviour and found that both economic and psychological factors help understand residential consumers' behaviour. Recently, when investigating consumer preference heterogeneity in supplier switching in relation to six non-price attributes of electricity services employing a latent class analysis, Ndebele et al. [39] found three different latent consumer classes, which confirms the importance of designing customised services in the strategies of energy suppliers.

Yang et al. [7] identified a consumer segment that is willing to pay more for renewable energy. Among factors influencing consumer preferences, socio-demographic characteristics are found to be important. Behavioural and attitudinal characteristics are also important drivers of consumer preference heterogeneity.

Our study augments the range of findings of previous studies examining consumer preferences for energy services in the residential energy market $[7,9]$ by studying the heterogeneity of consumer preferences for a core product (electricity) when the supplier also offers other energy products and services, where some of them are targeted to increase the energy efficiency of households. In comparison to other studies, our study examines both stated and revealed consumer preferences, which allows a cross-checking between hypothetical and actual behaviour, and thus enables a comprehensive analysis of complex consumer behaviour in the residential energy markets.

\section{Methods and Data}

\subsection{Methods}

To verify the two hypotheses, presented in the Introduction, a latent class analysis (LCA) is augmented by a latent class regression (LCR) model. For the first hypothesis, the LCA is used to identify a range of preferences for energy services that may cluster consumers into different segments (latent classes). To test the second hypothesis, the LCR model is employed to provide empirical verification of correlates with identified consumer segments in order to determine the consumer profile of each segment. Besides preferences, the LCR classifies consumers according to their behavioural and attitudinal characteristics toward energy.

The theoretical framework for analysing consumer preferences for energy services is based on a probabilistic approach for determining the unobserved (i.e., latent) class membership of individuals, named 'latent class analysis' (LCA) [40]. This is one of the most often used approaches for analysing consumer heterogeneity in the literature [41-43]. Since the importance of preferences for energy services may differ across underlying consumer classes, LCA is employed to capture this heterogeneity [44]. LCA allows the clustering of consumers into different classes on the basis of their expressed preferences and consequently enhances the understanding of consumer behavioural dynamics [45]. Moreover, LCA has the ability to integrate the information from a variety of factors such as attitudinal, perceptual, 
and other consumer characteristics into one model [46]. As a starting point, LCA assumes there exists a finite number of subgroups of individuals (i.e., classes of residential energy consumers) with heterogeneous preferences among groups and homogeneous preferences within groups [41]. Although the class membership of a consumer is unknown, the model probabilistically groups each consumer into a "latent class", which produces expectations of his/her responses to preference items (variables). These are 165 -point Likert scale items belonging to six dimensions of preferences for energy services that will be explained in more detail in Section 3.2.

The latent class model consists of $J$ variables (preference items), each of which contains $K_{j}$ possible outcomes for consumers $i=1, \ldots, N$. Each consumer has a finite set of possibilities for outcomes of size $\prod_{j \in J} K_{j}$ when scoring on all $J$ items. The probability that a consumer scores a particular set of outcomes for preference items assumes conditional independence of the outcomes is the product of probabilities for scoring a particular outcome across all items. We denote each outcome with $Y_{i j k}=1$ where the consumer $i$ gives the $k$ th response to the $j$ th variable, and $Y_{i j k}=0$ otherwise. The model then approximates the observed joint distribution of the preference items for a finite number of $R$ classes. With $\pi_{j r k}$, the class-conditional probability that a respondent in class $r=1, \ldots, R$ gives the $k$ th response on the $j$ th preference item is denoted. With $p_{r}$, we denote $R$ mixing proportions that provide weights in the estimation and $\sum_{r} p_{r}=1$ must hold. The latter values are prior probabilities of latent class membership.

Then, the probability that a consumer $i$ in class $r$ gives a particular set of $J$ responses for the preference items, while the conditional independence of the responses $Y$ given class membership is assumed, is the following:

$$
f\left(Y_{i} ; \pi_{r}\right)=\prod_{j=1}^{J} \prod_{k=1}^{K_{j}}\left(\pi_{j r k}\right)^{Y_{i j k}}
$$

The corresponding probability density function across all classes is then the following weighted sum:

$$
P\left(Y_{i} \mid \pi, p\right)=\sum_{r=1}^{R} p_{r} \prod_{j=1}^{J} \prod_{k=1}^{K_{j}}\left(\pi_{j r k}\right)^{Y_{i j k}}
$$

In the second part of the analysis, we employ a latent class regression (LCR) model which aims at predicting consumers' latent class memberships by the inclusion of covariates into the model [47]. The basic LCA model assumes that every consumer has the same prior probabilities of latent class membership, while the LCR model allows consumers' prior probability to vary depending upon their observed covariates. This approach is also known as the 'one-step' approach since it estimates the effects of covariates simultaneously as a part of the latent class model. Moreover, Bolck et al. [48] demonstrated that estimating the entire LCR model in a one-step approach is preferable to a step-by-step estimation since the latter produces biased coefficients estimates.

Following Swait [42], the unobservable or latent membership likelihood function of consumer $i$ belonging to a specific class $r$ (dependent variable) can be associated with consumers' socio-demographic and socio-economic characteristics, as well as with the observed behavioural and attitudinal profile (explanatory variables—covariates). This regression enables the estimation of the effects of covariates on predicting latent class membership [47].

Mixing proportions in the LCR model are denoted as $p_{r i}$ in order to reflect that these prior probabilities are now free to vary by consumer. Similarly as before, the following assumption has to be met: $\sum_{r} p_{r i}=1$ for each consumer (prior probabilities are constrained to be greater than zero and sum up to 1). Let $X_{i}$ represent the observed covariates for consumer $i$. $\beta_{r}$ is the vector of coefficients corresponding to the $r$ th latent class. $S$ is the set of covariates, and therefore vector $\beta_{r}$ has the length $S+1$ (one coefficient for each of the covariates together with a constant). In the estimation, the first latent class is usually selected as a "reference" class, and so is assumed that the log-odds of the latent class membership prior probabilities with respect to that class are linear functions of covariates. 
Since the covariates in the LCR model affect the probabilities of latent class membership, we can specify a link function between the two. Here, we specify that the underlying model is a multinomial logit model since the LCR model allows consumers' probabilities of latent class membership to vary upon their observed covariates. The latter is the case since the LCR model uses consumer-specific characteristics as covariates. In order to use the membership likelihood functions described above, which are random variables, the distribution of error terms must be specified. Swait [42] assumes that the error term is independently distributed across consumers in terms of the extreme value distribution, and thus the probability of a consumer $i$ belonging to the latent class $r$ can be rewritten as:

$$
p_{r i}=p_{r}\left(X_{i} ; \beta\right)=\frac{\exp \left(X_{i} \beta_{r}\right)}{\sum_{q=1}^{R} \exp \left(X_{i} \beta_{q}\right)}
$$

The LCR model estimates $R-1$ vectors of coefficients $\beta_{r}$, which represent the parameters of the model. Furthermore, the same as in the basic latent class model, the LCR model estimates the class-conditional outcome probabilities $\pi_{j r k}$. For the given estimates $\hat{\beta}_{r}$ and $\hat{\pi}_{j r k}$ of the aforementioned parameters $\left(\beta_{r}\right.$ and $\left.\pi_{j r k}\right)$, the posterior class membership probabilities in the LCR model, conditional on the observed values of the preference items, are obtained using Bayes' formula (in practice by replacing the $p_{r}$ from the basic latent class model with the function $p_{r}\left(X_{i} ; \beta\right)$ ):

$$
\hat{P}\left(r_{i} \mid X_{i} ; Y_{i}\right)=\frac{p_{r}\left(X_{i} ; \hat{\beta}\right) f\left(Y_{i} ; \hat{\pi}_{r}\right)}{\sum_{q=1}^{R} p_{q}\left(X_{i} ; \hat{\beta}\right) f\left(Y_{i}, \hat{\pi}_{q}\right)}
$$

where $r_{i} \in\{1, \ldots, R\}$. Note that the $\hat{\pi}_{j r k}$ are estimates of outcome probabilities conditional on class $r$. On the basis of the maximum posterior class membership probability, consumers are clustered into classes.

The latent class parameter $\beta_{r}$ is estimated by a maximum likelihood estimation using a modified expectation-maximisation algorithm with a Newton-Raphson step [49]. The log likelihood function is given by:

$$
\ln L(\beta \mid R)=\sum_{i=1}^{N} \ln \left(\sum_{r=1}^{R} p_{r}\left(X_{i} ; \beta\right) \prod_{j=1}^{J} \prod_{k=1}^{K_{j}}\left(\pi_{j r k}\right)^{Y_{i j k}}\right)
$$

When assessing the model fit and determining the appropriate number of latent classes $R$ for a given data set, there is a variety of different statistical tests available. In practice, the number of latent classes depends on both the model fit information, as well as on the explanatory power. We assess the model fit with several model fit indicators, including the Bayesian information criterion (BIC), the Akaike information criterion (AIC), the $\chi^{2}$ statistic, and the bootstrapped parametric likelihood ratio test (BPLRT). The quality of classification or entropy is also an important factor due to the fact that a higher value implies significant distinctions among classes [50]. There is no general rule saying which test is the most adequate. The decision depends on the usefulness of results and their interpretability. Although models with the lowest AIC, BIC, and the highest quality of classification (entropy) are preferred, there is usually a trade-off between the statistical significance (probability) and the practical significance (interpretability) of the results. For the best fitting latent class model, we therefore consider the values of AIC and BIC. A low value of AIC is desired to obtain the best classification. A low BIC value favours a small number of classes due to its sensitivity to the high number of parameters.

The presented model in our analysis is applied, first, to predict the class membership of consumers on the basis of their preferences for energy services, and second, to associate their membership with both individual consumer characteristics, as well as with information on their attitudinal and behavioural profiles. 


\subsection{The Sample and Data Description}

The proposed model is validated and estimated using the data collected from an online survey of electricity consumers of one of the largest energy suppliers in Slovenia, which also operates in more than 10 energy markets in central and southern Europe. For more than 50 years the company's main business was the sale of petroleum products in gas stations in Slovenia. After the energy markets liberalisation, the firm extended its portfolio with several energy fuels (electricity, liquefied petroleum gas (LPG), natural gas, heating oil) and other energy-related services (automatic meter reading, online billing system, sales of electric appliances and energy efficiency products, online shopping, and other customised offers for households). From its database of electricity consumers, 5466 consumers were randomly selected in order to gather the data with an online survey using a self-administered questionnaire in February 2016. The final sample consisted of 984 consumers-holders of an electricity supply contract with this supplier, which corresponds to an $18 \%$ response rate. The data were merged with the supplier's database containing consumers' information on their energy consumption of other fuels and the usage of other supplier's services.

The socio-demographic profile of consumers is presented in Table 1. A comparison between the survey sample $(\mathrm{N}=984)$ and the base sample $(\mathrm{N}=5466)$ was made to detect any potential discrepancy between the two in the following three variables known for both samples: gender, age, and average monthly electricity bill. After conducting $t$-tests of the equality of means between the two samples, we can conclude that the differences are not statistically significant. The representativeness of the survey sample in comparison to the base sample is thus fairly assured. Since data on electricity contract holders at the national level are not available, we additionally provide a comparison with the population. While the average monthly electricity bill and the household income closely correspond to the population values, differences are detected in the socio-demographic variables. However, several other descriptive statistics of the sample closely correspond with the population such as the distribution of dwelling types and the share of urban population [21]. This is to some extent expected as the characteristics of an average electricity contract holder do not match those of the general population. Electricity contract holders are primarily men, around 50 years old, which also affects the bias towards the household's size and their education level. We should bear this in mind when interpreting the results and generalising our findings.

Table 1. Socio-economic characteristics of the survey sample in comparison to the base sample and the population.

\begin{tabular}{cccc}
\hline Characteristics & Sample $\mathbf{( N ~ = 9 8 4 )}$ & Base Sample (N = 5466) & Population \\
\hline Gender & & & \\
Male & 63.3 & 63.4 & 49.1 \\
Female & 36.7 & 36.6 & 50.9 \\
Age & & & 6.4 \\
Younger than 25 years & 0.1 & 0.4 & 16.7 \\
26-35 Years & 10.5 & 10.5 & 18.4 \\
36-45 Years & 24.9 & 23.5 & 18.3 \\
46-55 Years & 29.4 & 26.6 & 17.7 \\
56-65 Years & 22.5 & 21.3 & 22.5 \\
Older than 65 Years & 12.6 & 13.7 & 32.6 \\
Number of household members & & & 25.1 \\
1 member & 7.5 & & 18.6 \\
2 members & 24.9 & & 15.2 \\
3 members & 22.5 & & 8.5 \\
4 members & 25.2 & & 11.9 \\
5+ members & 18.0 & & 63.4 \\
Education & & & 12.4 \\
\hline Vocational education & 1.9 & & \\
\hline
\end{tabular}


Table 1. Cont.

\begin{tabular}{|c|c|c|c|}
\hline Characteristics & Sample $(\mathrm{N}=984)$ & Base Sample $(\mathrm{N}=5466)$ & Population \\
\hline University and higher education & 26.9 & & 12.3 \\
\hline Do not know/ No answer & 5.1 & & 1 \\
\hline \multicolumn{4}{|l|}{ Monthly household income groups } \\
\hline Under $500 €$ & 2.0 & & / \\
\hline $500-1000 €$ & 10.9 & & / \\
\hline $1000-1500 €$ & 22.5 & & / \\
\hline $1500-3000 €$ & 33.8 & & / \\
\hline $3000 €$ or more & 9.2 & & / \\
\hline Do not know/No answer & 21.4 & & / \\
\hline Average Monthly household income $(€)$ & 1850.6 & & 1800.1 \\
\hline Average Monthly household electricity bill $(€)$ & 58.1 & 58.7 & 57.8 \\
\hline
\end{tabular}

Source: Statistical Office of the Republic of Slovenia [51].

The analysis was performed on 788 observations, as all missing values (except income) had to be excluded from the latent class regression analysis. This resulted in dropping 196 observations. In order to see if the survey sample $(\mathrm{N}=984)$ and the regression sample $(\mathrm{N}=788)$ are sufficiently similar, we tested for the statistical equality of explanatory variables' means included in the regression analysis. The results do not show significant differences between variables of the two samples. This indicates that the missing values do not present an important source of sample bias in our case. For the purpose of LCR, we constructed four dummy variables on the basis of income groups (see Table 1): low income, medium income, high income, and unknown income. The low-income group consists of two groups below $1000 €$, the medium income of two groups between $1000 €$ and $3000 €$, the high income of one group above $3000 €$, while the unknown income group includes all missing data observations. The medium income group represents the reference category in LCR.

Table 2 presents the descriptive statistics related to the consumption and usage of energy services. Overall consumer satisfaction with the energy supplier is measured on a 5-point Likert scale anchored by "very dissatisfied" (1) and "very satisfied (5)." In line with the results of previous studies [38], consumers' satisfaction rates are very high. The description of the variables related to the energy consumption is the following: the usage of additional services represents the monthly frequency of usage of a supplier's services; the usage of additional energy fuels is the number of additional energy sources used in the household (heating oil, gas, and/or biomass); average monthly consumption is the consumption of electricity recoded into five classes of consumption. Furthermore, three attitudinal variables are included to capture the environmental awareness and attitudes towards green energy and energy efficiency, and an additional four behavioural variables capture the energy-efficient behaviour of respondents. These variables are measured on a 5-point Likert scale except the last two, the number of household's investments in EE, and the number of household's EE activities which are constructed by summing the five binary variables described and presented in detail in Appendices A and B.

Table 2. Descriptive statistics related to the consumption and usage of energy services.

\begin{tabular}{|c|c|c|c|c|}
\hline Variables (Scale) & Mean & Standard Deviation & Min & Max \\
\hline Satisfaction with the energy supplier (1-5) & 4.38 & 0.69 & 1 & 5 \\
\hline Usage of additional services (1-6) & 2.73 & 1.21 & 1 & 6 \\
\hline Usage of additional energy fuels* $(0-3)$ & 1.23 & 0.53 & 0 & 3 \\
\hline Average monthly consumption (1-5) & 2.76 & 1.04 & 1 & 5 \\
\hline Interested in EE and in green energy (1-5) & 3.85 & 1.12 & 1 & 5 \\
\hline Environmental concern is important (1-5) & 2.18 & 1.43 & 1 & 5 \\
\hline Prepared to pay a $10 \%$ higher premium for green energy $(1-5)$ & 2.92 & 1.22 & 1 & 5 \\
\hline Using EE home appliances (1-5) & 4.26 & 0.84 & 1 & 5 \\
\hline Seeking ways to reduce energy costs $(1-5)$ & 4.46 & 0.79 & 1 & 5 \\
\hline Number of household's investments in EE (1-5) & 3.29 & 1.14 & 1 & 5 \\
\hline Number of household's EE activities (1-5) & 3.40 & 1.11 & 1 & 5 \\
\hline
\end{tabular}

* Note: Since this variable is taken from the supplier's database it enables us to check whether there is a statistically significant difference in means between the survey sample $(=1.23)$ and the base sample $(=1.24)$. The $t$-test with $p$-value $=0.734$ indicates that the means are not significantly different. 
The questionnaire was developed following a comprehensive literature review and exploratory interviews with marketing consultants of the collaborating energy supplier. The survey questionnaire consists of four sections. The first section contains questions regarding preferences for energy services, as well as questions about overall satisfaction with the supplier. The second section contains questions about consumer attitude and behaviour toward green energy and energy-efficient technologies. The third part contains a set of socio-economic and socio-demographic questions. In the last part, an examination of consumer loyalty behaviour was conducted. All questions are in a close-ended format.

The development of measurement scales and indicators is based on the theoretical framework reviewed in Section 2. Drawing on the literature, consumer preferences for energy services can be captured by six constructs: (1) core service quality, (2) service process quality, (3) low and transparent pricing, (4) brand reputation, (5) offer of additional EE services, and (6) offer of green energy. The details are given in Appendix C. These preferences are assessed by a multidimensional scale on a 5-point Likert scale [52]. The scale of importance of preferences for energy service constructs is anchored by "strongly disagree" to "strongly agree." The items of service quality and service process quality constructs have been adapted from the 22-item SERVQUAL scale [23] as well as from the specific scales on energy services [4] with our modifications and extensions to suit the needs of our research setting. We follow the recommended approach by authors of the scales arguing that, if relations between measured constructs are subsequently assessed, the measurement should be based on preferences and not exclusively on perceived results. Preferences for additional EE services are also measured as a multi-item construct on a 5-point Likert scale, following Hartmann and Apaolaza Ibáñez [4], on two items with an additional self-administered three items, which include specific services related to energy supply. To measure preferences for brand reputation and preferences for green energy, appropriate items were adapted from Fombrum et al. [53]. Measures of preferences for the low and transparent pricing were adapted from Lichtenstein et al. [54], and are also measured with a single item on a 5-point Likert scale.

Measurements of preference constructs utilised in our model may slightly differ from the literature outlined above as they were modified to fit the context of the energy service sector. Our modification was primarily aimed at providing a comprehensive collection of possible determinants of consumer preferences, as well as at considering the modalities of our research setting.

\section{Results}

In the first part of the analysis, the energy service preference items presented in Appendix $C$ are utilised in a latent class analysis (LCA) to determine the class membership probability. We use single-item scores rather than factor analysis scores in LCA, since we assume that single items might add more detailed information about scoring patterns and thus improve this probabilistic assignment to preference classes. The number of latent classes depends on both the model fit information and explanatory power. In what follows, we assess various numbers of LCA classes with several model fit indicators. All empirical estimations in our study were conducted using R statistical software [55] Specifically, LCA was performed using R's package poLCA [56].

When estimating our model with LCA, we assessed one to five class solutions. For each class solution, we applied the assessment procedure 10 times (with random starting values), and chose the one with the best fit. Best scores for each class solution are presented in Table 3. The results show that BIC favours a 3-class solution, while AIC prefers a 5-class solution. Although both BIC and AIC suggest a different class solution, the entropy value indicates the smaller one (3-class solution) as more appropriate. As mentioned, the choice of the number of latent consumer classes should rest on the interpretability of the results for a particular case. Three models were taken into consideration since they provide the highest statistical significance. First, we examined the models with four and five consumer classes. However, we realised that differences in values of BIC and AIC became smaller after the three-class solution, indicating a lack of significant improvement in classification by using the four-class solution. We also carefully examined the four-class solution and noticed that two of 
the classes were small with almost no difference. Thus, we decided to choose a three-class solution, because it gives the most reasonable explanation, and the size of each consumer class is sufficiently large for a further examination. The three-class solution also corresponds to our expectations after conducting a control cluster analysis.

Table 3. Statistics for determining the number of consumer classes.

\begin{tabular}{cccccc}
\hline Number of Classes & Npar & LL & AIC & BIC & Entropy \\
\hline 1 & 64 & $-13,728.21$ & $27,584.42$ & $27,883.26$ & \\
2 & 147 & $-12,470.228$ & $25,234.457$ & $25,920.873$ & 0.87 \\
3 & 230 & $-12,011.456$ & $24,482.912$ & $25,556.896$ & 0.88 \\
4 & 313 & $-11,744.324$ & $24,114.649$ & $25,576.202$ & 0.86 \\
5 & 396 & $-11,551.138$ & $23,894.276$ & $25,743.398$ & 0.85 \\
\hline
\end{tabular}

Note: Npar = number of free parameters; LL = log likelihood; AIC = Akaike information criterion; BIC = Bayesian information criterion.

To support our decision, we performed also the bootstrapped parametric likelihood ratio test [57]. This test compares the increase in the model fit between the $k-1$ and $k$ class model. In our case, we compare the three-class with the four-class model, where the null hypothesis sets the probability of an individual being in the fourth class to zero. The $p$-value of 0.078 indicates that we failed to reject the null hypothesis, implying that the restricted three-class solution is not rejected.

The posterior class assignment probability for the 3-class solution is presented in Table 4 . The numbers in the columns are the average probabilities of belonging to each class for each class of individuals. For example, 0.95 means that individuals in class 1 have on average a $95 \%$ probability of belonging to this class, compared with $3 \%$ and $2 \%$ for the other two classes, respectively. Moreover, based on probabilities assigned for belonging to a given class, it is shown how well the respondents are classified in each of the three classes. According to diagonal values of the classification matrix (Table 4), the accuracy of classification is relatively high across classes. It varies from $93 \%$ to $96 \%$.

Table 4. Assignment probability by class.

\begin{tabular}{cccc}
\hline & \multicolumn{3}{c}{ Assigned Class Probability to Each Class } \\
Assigned Class Membership * & Class 1 & Class 2 & Class 3 \\
\hline Class 1 & 0.95 & 0.04 & 0.07 \\
Class 2 & 0.03 & 0.96 & 0.00 \\
Class 3 & 0.02 & 0.00 & 0.93 \\
\hline uals were classified according to the highest estimated probability of belonging to a specific class.
\end{tabular}

Further, Table 5 compares identified consumer classes by the six dimensions of preferences for energy services. The results of LCA reveal that consumers are heterogeneous when comparing different dimensions of energy services. As expected, the most important dimension for all consumer classes is the core service quality, i.e., the reliability of services. This could be explained by the fact that energy and particularly electricity are necessity goods, so a reliable supply is viewed as a fundamental requirement for the offer of any supplier. Core service quality is closely followed by the service process quality and low and transparent prices, while the other three dimensions on average are given somewhat less importance. Differences in preferences among the three classes can also be observed. Class 1 , the largest consumer group, appears to represent regular consumers. It predominantly focuses on the core service quality, service process quality, and low and transparent pricing, while in comparison to other two classes it attributes the lowest importance to the other three dimensions of the supplier's offer. In contrast, compared to other two classes, class 2 attributes the highest values to the offer of additional EE services, the offer of green energy, as well as brand reputation, while evaluating the first three dimensions similarly as class 1 . In comparison to other two classes, class 3 does not reach the highest score in any of the dimensions; it scores the lowest on the first three dimensions and between the other two classes in the last three dimensions. 
Table 5. Comparisons of consumer classes.

\begin{tabular}{cccccc}
\hline Description & Class 1 (48.0\%) & Class 2 (36.0\%) & Class 3 (16.0\%) & F-test & $p$-Value \\
\hline Mean (and Standard Error) & & & & & \\
1. Core service quality & $4.71(0.69)$ & $4.73(0.53)$ & $4.62(0.80)$ & 62.03 & $<0.001$ \\
2. Service process quality & $4.61(0.51)$ & $4.57(0.51)$ & $4.48(0.78)$ & 466.90 & $<0.001$ \\
3. Low and transparent pricing & $4.60(0.58)$ & $4.54(0.57)$ & $4.51(0.80)$ & 108.4 & $<0.001$ \\
4. Brand reputation & $3.88(1.13)$ & $4.05(1.04)$ & $3.96(1.15)$ & 134.1 & $<0.001$ \\
5. Offer of additional EE services & $3.77(0.74)$ & $3.95(0.73)$ & $3.80(0.88)$ & 262.5 & $<0.001$ \\
6. Offer of green energy & $3.66(1.17)$ & $3.85(1.11)$ & $3.77(1.24)$ & 74.65 & $<0.001$ \\
\hline
\end{tabular}

The analysis of variance (ANOVA) with the corresponding F-test and $p$-values reported in Table 5 allows rejecting the null hypotheses that all group means are equal. In addition, we conducted a comparison of group means with $t$-tests. The tests show that significant differences between class 1 and class 2 are found in variables "Brand reputation" and "Offer of green energy," between class 1 and class 3 in "Service process quality," and between class 2 and class 3 in "Offer of additional EE services."

The three consumer classes have been identified on the basis of the importance attributed to six different types of preferences for energy services. To characterise these consumers in terms of their attitude and behaviour toward green energy and energy-efficient technologies, as well as in terms of their socio-demographic and socio-economic profiles, the LCA is augmented with the LCR model to include the respective explanatory variables. These variables have been commonly suggested in marketing literature on consumer segmentation [58]. An empirical review of studies examining the correlation of these segmentation variables with green behaviour has been, for example, provided in Getzner and Grabner-Kraüter [59]. Table 6 presents the results of the latent class regression. The results show significant differences between class 2 and the other two consumer classes when considering their energy-efficient behaviour, as well as their intention to adopt green energy programs.

Table 6. Estimation results of the latent class regression.

\begin{tabular}{|c|c|c|c|c|}
\hline Explanatory Variables & \multicolumn{2}{|c|}{ Energy-Efficient vs. Regular } & \multicolumn{2}{|c|}{ Dissatisfied vs. Regular } \\
\hline \multicolumn{5}{|l|}{ Coefficient and Standard Error } \\
\hline Intercept & $-7.99 * * *$ & 1.591 & $3.850 *$ & 2.127 \\
\hline Gender & -0.310 & 0.233 & 0.471 & 0.369 \\
\hline Age & -0.001 & 0.010 & -0.010 & 0.014 \\
\hline Number of household members & -0.142 & 0.107 & -0.091 & 0.140 \\
\hline \multicolumn{5}{|l|}{ Household income } \\
\hline - Low income & -0.126 & 0.345 & 0.172 & 0.550 \\
\hline - High income & -0.017 & 0.445 & 0.762 & 0.537 \\
\hline - Unknown income & -0.012 & 0.291 & 0.419 & 0.408 \\
\hline Education & $-0.282 * * *$ & 0.107 & 0.196 & 0.160 \\
\hline Satisfaction with the energy supplier & $0.848^{* * *}$ & 0.205 & $-0.782 * * *$ & 0.249 \\
\hline Usage of additional services & -0.017 & 0.105 & -0.084 & 0.137 \\
\hline Usage of additional energy fuels & -0.346 & 0.249 & 0.540 & 0.351 \\
\hline Average monthly consumption & 0.130 & 0.116 & 0.183 & 0.188 \\
\hline Interested in EE and in green energy & $0.285^{* *}$ & 0.113 & -0.127 & 0.172 \\
\hline Environmental concern is important & $0.811^{* * *}$ & 0.166 & -0.158 & 0.220 \\
\hline Prepared to pay a $10 \%$ higher premium for green energy & 0.128 * & 0.078 & 0.023 & 0.135 \\
\hline Using EE home appliances & $0.302 *$ & 0.169 & $-0.402 *$ & 0.230 \\
\hline Seeking ways to reduce energy costs & -0.022 & 0.098 & -0.171 & 0.163 \\
\hline Number of household's investments in EE & -0.098 & 0.102 & -0.209 & 0.142 \\
\hline Number of household's EE activities & $0.224^{* *}$ & 0.106 & -0.073 & 0.162 \\
\hline
\end{tabular}

The overall model has 788 observations: 788, 230 estimated parameters and 558 residual degrees of freedom. $\operatorname{AIC}(3)=24482.91, \operatorname{BIC}(3)=25556.9, \chi^{2}(3)=5.418763 \mathrm{e}(+15)$

Note: EE-energy efficiency. Complete descriptions of items are given in Appendices A, B and D. * Significant at the 0.10 level; $^{* *}$ Significant at the 0.05 level; ${ }^{* * *}$ Significant at the 0.01 level.

Based on the latent class regression results (Table 6), the three consumer classes could be categorised as "regular" consumers (48\%), "energy-efficient" consumers (36\%), and "dissatisfied" consumers $(16 \%)$. The largest class of regular consumers presents the reference class in the latent class multinomial regression model. Several variables significantly influence the membership between energy-efficient class and regular class: showing an interest in EE and green energy, finding environmental concern important, being prepared to pay a $10 \%$ higher premium for green energy, and using EE home 
appliances increases the likelihood of being a member of an energy-efficient class. Compared to regular consumers, energy-efficient consumers are also significantly more satisfied with the supplier. Exhibiting more energy-saving habits in households (e.g., using electrical appliances during lower tariffs, turning lights off when not in use, avoiding a stand-by mode, washing at lower temperatures, and instantly closing the doors of cooling appliances after use) also positively impacts the membership of the energy-efficient class. Since both green energy and energy efficiency programs contribute to reducing greenhouse gas emissions, consumers that support either of these two issues can be considered environmentally friendly. This is additionally illustrated in Appendix D, where three consumer classes are descriptively compared with respect to their green and energy-efficient attitudes and behaviour.

When examining the differences between the socio-demographic profiles of the two largest classes, the results reveal a significant and negative impact of education on the membership in energy-efficient class, while household income and the number of households members are not significant. The main difference between the regular and dissatisfied consumer segment has been found in the significantly lower satisfaction with the supplier of the latter group. This is also clearly seen from the descriptive statistics, where the average satisfaction rate of regular consumers closely corresponds to the sample mean (4.35), while it is found to be considerably lower in the dissatisfied consumer segment (3.93). Considering the energy efficiency, using EE home appliances frequently decreases the likelihood of being members of the dissatisfied segment. Other explanatory variables do not point to significant differences between these two groups.

\section{Discussion and Conclusions}

This paper clearly reveals heterogeneity in residential consumer preferences for energy supplier offers, thereby re-confirming the findings of several other studies examining consumer preference heterogeneity $[7,9,60]$. When accounting for residential energy consumer attitudes and behaviour toward green energy and energy efficiency, and their socio-demographic and socio-economic characteristics, the paper establishes that energy consumers can effectively be segmented into three different groups: regular consumers, energy-efficient consumers, and dissatisfied consumers. The identified energy-efficient segment also shows the highest preference for additional energy-efficient services and green energy. The results of our study therefore support both hypotheses.

Some managerial implications can be derived from our study. First, suppliers should carefully analyse consumer preferences to design appropriate marketing strategies in the rapidly changing energy markets. These findings complement the findings of the Accenture study [60] that marketing strategies in the transformed energy world require a novel approach to consumer segmentation. They should be based on non-traditional criteria, where suppliers should understand consumers' values based on their attitudes and behaviour and their sense of environmental responsibility, rather than continuing to offer traditional "low-cost services" combined with the minimisation of credit risk [60]. Differentiated marketing campaigns and service offers are needed to maximise revenues and meet mandatory energy-saving targets at consumer sites at the lowest cost. Focusing primarily on the energy-efficient consumer segment with customised offers of additional services is a more beneficial approach than addressing all consumer segments with the "one type fits all" retention and acquisition strategy.

Furthermore, as expected, our results for consumers that are the most inclined towards energy efficiency reveal that these consumers are interested in green energy programs and are willing to pay a higher premium for green energy. Therefore, there is no gap between stated and revealed preferences in this consumer segment, as their actions are in line with their intentions. Conversely, consumers in the regular class support energy efficiency and green energy; however, their actions regarding green energy do not follow their intentions. The resulting gap between the stated and revealed preferences for green energy is to some extent expected, as the willingness to pay is often found to be overestimated [61] and strategic answers may appear in respondents' answers. One possible explanation could be that consumers may not be interested in green energy because they are suspicious 
of the actual environmental performance of the supplier [5]. Another reason could be their concern about the risks associated with the increasing share of green energy, which can reduce the reliability of supply, and which, together with low price, is according to our findings their preferred attribute of energy services. Significant drops in public acceptance of renewables also happen when consumers consider their drawbacks on a concrete (local) level [62].

The energy-efficient consumers are also less educated compared to regular consumers. This is a rather surprising result, as education is typically believed to be positively correlated with environmental awareness. Further examination would be needed to see if the education effect was offset by the social status effect, as Belaïd et al. [14] explained when they failed to find education among influential factors of residential energy consumption. A higher social status inspires less energy-saving behaviour due to living comfort priorities.

While energy-efficient consumers are already prepared to invest in energy efficiency, regular consumers have to be motivated and persuaded to pursue such behaviour. The same pertains to the less satisfied consumers. More personalised and detailed information on available options is needed to induce energy-saving behavioural changes [31]. Moreover, technology adoption and ecological use can be enhanced through education on product features and activation of consumer's pro-environmental behaviour [63]. Consumer retention programs should also focus more intensively on these two segments of consumers, as this study shows that regular consumers tend to be less satisfied with the supplier compared to the energy efficiency group. The satisfaction with the supplier is a particularly critical issue in the dissatisfied group, which demonstrates significantly lower satisfaction with the supplier than the regular group. Given the fact that the dissatisfied group encompasses a small consumer base $(16.0 \%)$, it remains to be answered if paying more attention to this segment pays off. Targeting the other two consumer segments with additional customised offers and customer relationship programs (CRM) is a more promising strategy for the supplier. To increase the satisfaction level of the least satisfied group, which may prevent switching the supplier, more thoroughly designed customer relationship management programs should be designed.

It should also be noted that despite shrinking price differentials among suppliers, price competition still plays a significant role in the residential electricity market [17]. Despite other priorities, all three identified consumer groups rank the reliability of supply, service process quality, and low-priced services the highest in comparison to other preference attributes. Suppliers, thus, should not neglect the reliable low price offers at the expense of prioritising other marketing strategies associated with additional offers complemented with adequate communication campaigns. The consumer switching flows observed in the Slovenian electricity market [15] supports the found importance of preferences for low-priced energy services in our study. However, because price differences among suppliers are shrinking, preferences for low prices and related savings may gradually become less crucial for consumers when comparing different offers.

Although our study provides valuable insights into how suppliers should design their marketing strategies to address the needs of various consumer groups, and is therefore in particular informative for suppliers, it also provides valuable insights for policymakers. While policymakers usually design policies looking at customers as a homogenous group, this study clearly reveals that the same policy measures may achieve different effectiveness in different consumer segments. If the suppliers get to know their customers through customer relationship management involving, for example, loyalty programs, they could help policymakers implement energy policy measures more effectively. Their energy-saving offers could be directly aimed at promoting the involvement of the most energy-efficient consumers, while publicly designed information campaigns should primarily target consumers who are less inclined to exhibit energy-efficient behaviour.

Effectively addressing the energy-efficient consumer group may also serve as a useful managerial tool to effectively implement mandatory energy efficiency targets, contributing to the national economy sustainability goals [15]. With expanded offers, energy suppliers could provide added value to their consumers while increasing revenues and meeting energy efficiency policy objectives. 
More challenging for policymakers are the other two consumer groups, less interested in energy efficiency and representing the majority of the consumer base. Policymakers should be encouraged to carry out publicly supported studies that reveal reasons for their lower preferences and commitment to energy efficiency. As these consumers may not be informed about different energy efficiency options, publicly funded information campaigns can be a useful tool to complement the dissemination of information embedded in supplier's marketing strategies. Information on the environmental impacts of their energy use should be part of these campaigns, as many do not link, for example, their electricity consumption (as opposed to gasoline) to the environment [60]. As consumers also show a strong preference for low prices, these campaigns can also inform them that searching for a low price is not the only way to reduce energy costs. A clear message should be conveyed to them that the installation of EE technologies and appliances could serve the same goal, as their use ultimately translates into lower energy bills. The publicly supported information campaigns should also disseminate information and promote the use of publicly funded programs (such as subsidies, grants, lower interest rates, other fiscal incentives, and public audits) that are available in many countries as, for example, a lack of finances and inability to afford appear among key barriers to the EE home retrofits [64-66]. Such information and awareness-raising campaigns would simultaneously promote both behavioural changes in energy use and technically related interventions including building retrofits.

Finally, some limitations of the study should also be noted that might limit the generalisation of results. This study was done on a relatively small sample of the residential electricity consumer base of one energy supplier. Although the sample is representative of the consumer base of this supplier, it would be useful to further check the results by expanding the consumer base and including other energy suppliers in the market. Replicating the study on residential energy consumers in other countries may also bring insights into country-specific modalities in consumer preferences. However, our findings largely support the aforementioned Accenture's study [60] conducted over a much wider geographical area and larger consumer numbers.

Author Contributions: J.D.: Conceptualization, Investigation, Methodology, Software, Data curation, Writing-original draft, Validation. N.H.: Conceptualization, Investigation, Methodology, Supervision, Writing-review \& editing, Validation. J.Z.: Conceptualization, Investigation, Methodology, Supervision, Writing - review \& editing, Validation. All authors have read and agreed to the published version of the manuscript.

Funding: This research was sponsored by the Slovenian Research Agency (Research Programme P5-0117).

Acknowledgments: The paper benefited from discussions at the 16th IAEE European Conference held in 2019 in Ljubljana.

Conflicts of Interest: The authors declare no conflict of interest.

\section{Appendix A}

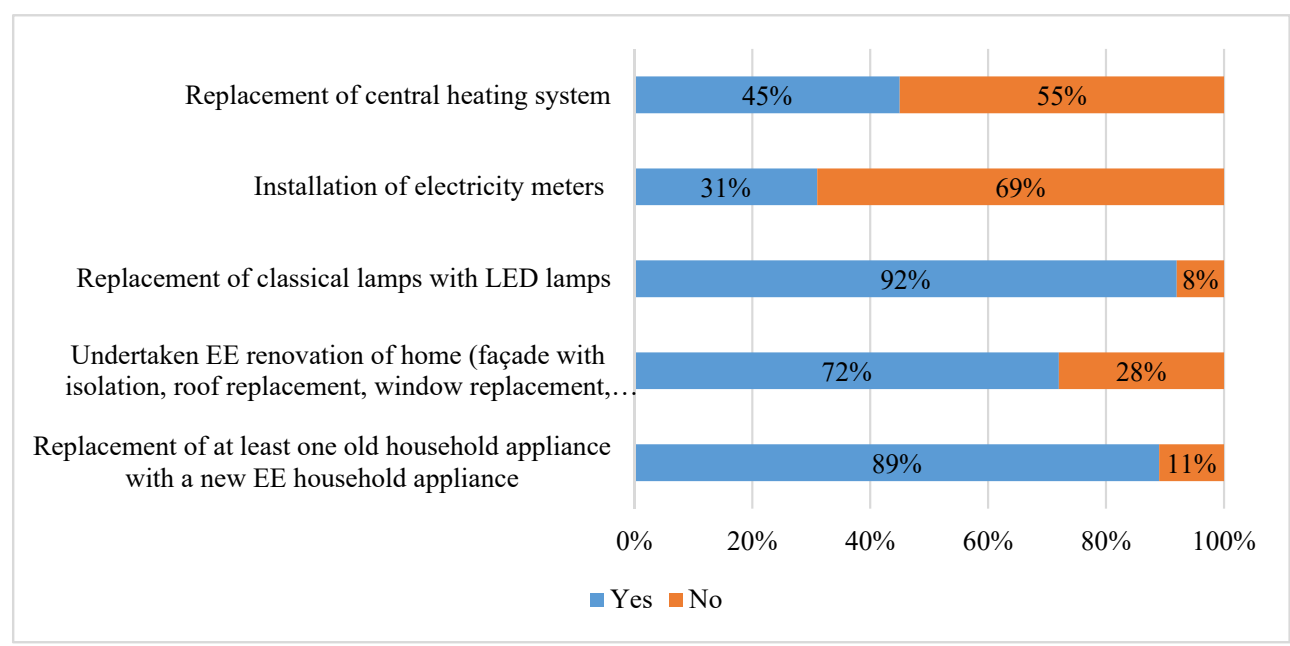

Figure A1. Distribution of consumers' energy-efficient investments. 


\section{Appendix B}

Completely turning off devices when not in use (no 'stand by' mode)

Washing at lower temperature

Using household appliances during lower electricity tariff

Instantly closing doors of cooling appliances after use

Turning off lights when not in the room

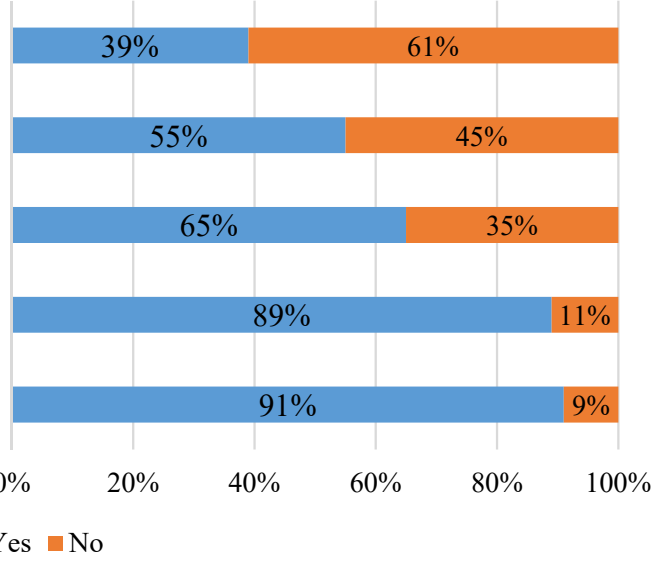

Figure A2. Distribution of responses on consumers' energy-efficient behaviour.

\section{Appendix C}

Table A1. Distribution of measurements of preferences for energy services.

\begin{tabular}{|c|c|c|c|c|c|c|}
\hline Description & $\begin{array}{l}\text { Mean (Standard } \\
\text { deviation) }\end{array}$ & $\begin{array}{c}\text { Totally } \\
\text { Disagree N (\%) }\end{array}$ & $\begin{array}{l}\text { Disagree } \\
\text { N (\%) }\end{array}$ & $\begin{array}{l}\text { Neither Agree nor } \\
\text { Disagree N (\%) }\end{array}$ & Agree N (\%) & $\begin{array}{c}\text { Totally Agree } \\
\text { N (\%) }\end{array}$ \\
\hline $\begin{array}{l}\text { 1. Core service quality } \\
\text { Offering reliable, } \\
\text { uninterrupted services }\end{array}$ & $4.71(0.67)$ & $9(0.9)$ & $7(0.7)$ & $44(4.5)$ & $145(14.7)$ & $779(79.2)$ \\
\hline $\begin{array}{l}\text { 2. Service process quality } \\
\text { Organising a network of firms }\end{array}$ & & & & & & \\
\hline $\begin{array}{c}\text { providing repair of } \\
\text { household appliances }\end{array}$ & $4.76(0.57)$ & $4(0.4)$ & $3(0.3)$ & $35(3.6)$ & $142(14.4)$ & $800(81.3)$ \\
\hline $\begin{array}{l}\text { Company is a } \\
\text { consumer-friendly company }\end{array}$ & $4.52(0.76)$ & $8(0.8)$ & $10(1)$ & $80(8.1)$ & $254(25.8)$ & $632(64.2)$ \\
\hline Rewarding consumer loyalty & $4.64(0.66)$ & $5(0.5)$ & $6(0.6)$ & $56(5.7)$ & $202(20.5)$ & $715(72.7)$ \\
\hline $\begin{array}{l}\text { Free-of-charge help to } \\
\text { the consumers }\end{array}$ & $4.59(0.71)$ & $5(0.5)$ & $12(1.2)$ & $61(6.2)$ & $222(22.6)$ & $684(69.5)$ \\
\hline $\begin{array}{l}\text { Offering advice on reducing } \\
\text { electricity consumption }\end{array}$ & $4.39(0.87)$ & $16(1.6)$ & $20(2.0)$ & 101(10.3) & $274(27.8)$ & $573(58.2)$ \\
\hline 3. Low and transparent pricing & & & & & & \\
\hline Offering the lowest price & $4.65(0.68)$ & $6(0.6)$ & $7(0.7)$ & $59(6)$ & $179(18.2)$ & $733(74.5)$ \\
\hline $\begin{array}{l}\text { The company's bill is clear } \\
\text { and transparent } \\
\text { 4. Brand reputation }\end{array}$ & $4.50(0.80)$ & $11(1.1)$ & $13(1.3)$ & $87(8.8)$ & $237(24.1)$ & $636(64.6)$ \\
\hline $\begin{array}{l}\text { The company has a } \\
\text { great reputation }\end{array}$ & $3.93(1.11)$ & $48(4.9)$ & $53(5.4)$ & 193(19.6) & $311(31.6)$ & $379(38.5)$ \\
\hline 5. Offer of additional EE services & & & & & & \\
\hline $\begin{array}{l}\text { Offering multiple tariff } \\
\text { billing systems }\end{array}$ & $4.06(1.11)$ & $43(4.4)$ & $52(5.3)$ & $164(16.7)$ & $273(27.7)$ & $452(45.9)$ \\
\hline $\begin{array}{l}\text { Offering tailored offers to } \\
\text { household specifications }\end{array}$ & $4.01(1.00)$ & $34(3.5)$ & $38(3.9)$ & $167(17)$ & $386(39.2)$ & $359(36.5)$ \\
\hline $\begin{array}{l}\text { Offering an online electricity } \\
\text { bill payment }\end{array}$ & $4.18(0.99)$ & $28(2.8)$ & $34(3.5)$ & $140(14.2)$ & $314(31.9)$ & $468(47.6)$ \\
\hline $\begin{array}{l}\text { Offering an online consumption } \\
\text { monitoring system }\end{array}$ & $4.18(0.99)$ & $23(2.3)$ & $40(4.1)$ & 148(15) & $302(30.7)$ & $471(47.9)$ \\
\hline $\begin{array}{l}\text { Offering a specialised shop with } \\
\text { electric appliances }\end{array}$ & $3.27(1.27)$ & $118(12)$ & $142(14.4)$ & $283(28.8)$ & $242(24.6)$ & $199(20.2)$ \\
\hline $\begin{array}{l}\text { Offering an energy } \\
\text { performance certificate } \\
\text { 6. Offer of green energy }\end{array}$ & $3.21(1.29)$ & $141(14.3)$ & $120(12.2)$ & $305(31)$ & $224(22.8)$ & 194(19.7) \\
\hline Offering green energy & $3.72(1.17)$ & $63(6.4)$ & $78(7.9)$ & $231(23.5)$ & $310(31.5)$ & $302(30.7)$ \\
\hline
\end{tabular}




\section{Appendix D}

Table A2. Comparison of environmental awareness and EE behaviour between consumer classes.

\begin{tabular}{cccc}
\hline Description & Class 1 & Class 2 & Class 3 \\
\hline Mean (Standard deviation) & & & \\
Interested in EE and in green energy & $3.76(1.00)$ & $4.28(1.05)$ & $3.50(1.05)$ \\
Environmental concern is important & $2.08(1.31)$ & $2.50(1.74)$ & $2.06(1.15)$ \\
Using EE home appliances & $2.93(1.08)$ & $3.28(1.41)$ & $2.43(1.09)$ \\
Seeking ways to reduce energy costs & $4.09(0.76)$ & $4.66(0.63)$ & $3.77(1.00)$ \\
Number of household's investments in EE & $4.42(0.70)$ & $4.77(0.59)$ & $3.96(0.94)$ \\
Number of household's EE activities & $3.35(1.03)$ & $3.35(1.16)$ & $2.98(1.20)$ \\
\end{tabular}

Note: Differences in means of almost all variables across the three classes are statistically significant, except for variables "Number of household's investment in EE" between class 1 and class 2, and variables "Environmental concern is important," and "Prepared to pay a 10\% higher premium for green energy" between class 1 and class 3 .

\section{References}

1. Newbery, D.M. Towards a green energy economy? The EU Energy Union's transition to a low-carbon zero subsidy electricity system-Lessons from the UK's Electricity Market Reform. Appl. Energy 2016, 179, 1321-1330. [CrossRef]

2. IEA. Empowering Customer Choice in Electricity Markets; International Energy Agency: Paris, France, 2011.

3. McDaniel, T.M.; Groothuis, P.A. Groothuis, Retail competition in electricity supply-Survey results in North Carolina. Energy Policy 2012, 48, 315-321. [CrossRef]

4. Hartmann, P.; Ibáñez, V.A. Managing customer loyalty in liberalized residential energy markets: The impact of energy branding. Energy Policy 2007, 35, 2661-2672. [CrossRef]

5. Wüstenhagen, R.; Bilharz, M. Green energy market development in Germany: Effective public policy and emerging customer demand. Energy Policy 2006, 34, 1681-1696. [CrossRef]

6. Hartmann, P.; Apaolaza-Ibáñez, V. Consumer attitude and purchase intention toward green energy brands: The roles of psychological benefits and environmental concern. J. Bus. Res. 2012, 65, 1254-1263. [CrossRef]

7. Yang, Y.; Solgaard, H.S.; Haider, W. Value seeking, price sensitive, or green? Analyzing preference heterogeneity among residential energy consumers in Denmark. Energy Res. Soc. Sci. 2015, 6, 15-28. [CrossRef]

8. Waechter, S.; Sütterlin, B.; Siegrist, M. Decision-Making Strategies for the Choice of Energy-friendly Products. J. Consum. Policy 2016, 40, 81-103. [CrossRef]

9. Kaenzig, J.; Heinzle, S.L.; Wustenhagen, R. Whatever the customer wants, the customer gets? Exploring the gap between consumer preferences and default electricity products in Germany. Energy Policy 2013, 53, 311-322. [CrossRef]

10. Frederiks, E.R.; Stenner, K.; Hobman, E.V. Household energy use: Applying behavioural economics to understand consumer decision-making and behaviour. Renew. Sustain. Energy Rev. 2015, 41, 1385-1394. [CrossRef]

11. Richter, M. Utilities' business models for renewable energy: A review. Renew. Sustain. Energy Rev. 2012, 16, 2483-2493. [CrossRef]

12. Lewis, P. World Energy Retail Market Rankings 2012; VaasaETT: Helsinki, Finland, 2012.

13. Belaïd, F.; Garcia, T. Understanding the spectrum of residential energy-saving behaviours: French evidence using disaggregated data. Energy Econ. 2016, 57, 204-214. [CrossRef]

14. Belaïd, F.; Roubaud, D.; Galariotis, E. Features of residential energy consumption: Evidence from France using an innovative multilevel modelling approach. Energy Policy 2019, 125, 277-285. [CrossRef]

15. Energy Agency. Report on the Energy Sector in Slovenia for 2019, 2020. Available online: https://www.agen-rs.si/documents/54870/68629/Report-on-the-energy-sector-in-Slovenia-for-2019/ce1c3cd8489a-401d-9a1a-502a7c5715e4 (accessed on 20 November 2020).

16. Energy Agency. Report on the Energy Sector in Slovenia for 2016, 2017. Available online: https://www.agen-rs.si/documents/54870/68629/Report-on-the-energy-sector-in-Slovenia-for-2016/de8cc94fb3f6-4d32-8e79-ce3b0ec386f5 (accessed on 6 May 2020).

17. Energy Agency. Report on the Energy Sector in Slovenia for 2015, 2016. Available online: https://www.agen-rs.si/documents/54870/68629/Report-on-the-energy-sector-in-Slovenia-for-2015/f1302ae07267-4ae7-b74d-7ce8c4323043 (accessed on 15 May 2020). 
18. European Council. EED-2012/27/EU, Directive 2012/27/EU of the European Parliament and of the Council of 25 October 2012 on Energy Efficiency, Amending Directives 2009/125/EC and 2010/30/EU and Repealing Directives 2004/8/EC and 2006/32/EC; European Council: Brussels, Belgium, 2012.

19. Yoo, S.; Eom, J.; Han, I. Factors Driving Consumer Involvement in Energy Consumption and Energy-Efficient Purchasing Behavior: Evidence from Korean Residential Buildings. Sustainability 2020, 12, 5573. [CrossRef]

20. Cherry, T.L.; McEvoy, D.M.; Westskog, H. Cultural worldviews, institutional rules and the willingness to participate in green energy programs. Resour. Energy Econ. 2019, 56, 28-38. [CrossRef]

21. Dolšak, J.; Hrovatin, N.; Zorić, J. Can loyalty programs be effective in promoting integrated energy services? Evidence from Slovenian electricity consumers. Energy Res. Soc. Sci. 2019, 48, 246-256. [CrossRef]

22. Hille, S.; Weber, S.; Brosch, T. Consumers' preferences for electricity-saving programs: Evidence from a choice-based conjoint study. J. Clean. Prod. 2019, 220, 800-815. [CrossRef]

23. Parasuraman, A.; Zeithaml, V.; Berry, L. SERVQUAL: A multiple-item scale for measuring consumer perceptions of service quality. J. Retail. 1988, 64, 12-40.

24. Büscher, C.; Sumpf, P. Trust and confidence as socio-technical problems in the transformation of energy systems. Energy Sustain. Soc. 2015, 5, 34. [CrossRef]

25. Aaker, D. Building Strong Brands; Free Press: New York, NY, USA, 1996.

26. Yang, Y.; Solgaard, H.S. Exploring residential energy consumers' willingness to accept and pay to offset their CO2emission. Int. J. Energy Sect. Manag. 2015, 9, 643-662. [CrossRef]

27. Pothitou, M.; Hanna, R.F.; Chalvatzis, K.J. Environmental knowledge, pro-environmental behaviour and energy savings in households: An empirical study. Appl. Energy 2016, 184, 1217-1229. [CrossRef]

28. Ohler, A.M.; Billger, S.M. Does environmental concern change the tragedy of the commons? Factors affecting energy saving behaviors and electricity usage. Ecol. Econ. 2014, 107, 1-12. [CrossRef]

29. Barr, S.; Gilg, A.W.; Ford, N. The household energy gap: Examining the divide between habitual- and purchase-related conservation behaviours. Energy Policy 2005, 33, 1425-1444. [CrossRef]

30. Belaï, F. Understanding the spectrum of domestic energy consumption: Empirical evidence from France. Energy Policy 2016, 92, 220-233. [CrossRef]

31. Ek, K.; Söderholm, P. The devil is in the details: Household electricity saving behavior and the role of information. Energy Policy 2010, 38, 1578-1587. [CrossRef]

32. Dougherty, A.; Van De Grift, S.C. Behavioral energy feedback program evaluations: A survey of current knowledge and a call to action. Energy Effic. 2016, 9, 899-909. [CrossRef]

33. Blum, H. The economic efficiency of energy-consuming equipment: A DEA approach. Energy Effic. 2014, 8, 281-298. [CrossRef]

34. Stern, P.C. How can social science research become more influential in energy transitions? Energy Res. Soc. Sci. 2017, 26, 91-95. [CrossRef]

35. Huh, S.-Y.; Jo, M.; Shin, J.; Yoo, S.-H. Impact of rebate program for energy-efficient household appliances on consumer purchasing decisions: The case of electric rice cookers in South Korea. Energy Policy 2019, 129, 1394-1403. [CrossRef]

36. Troiano, S.; Vecchiato, D.; Marangon, F.; Tempesta, T.; Nassivera, F. Households' Preferences for a New 'Climate-Friendly' Heating System: Does Contribution to Reducing Greenhouse Gases Matter? Energies 2019, 12, 2632. [CrossRef]

37. Parasuraman, A.; Berry, L.L.; Zeithaml, V.A. Understanding Customer Expectations of Service. Sloan Manag. Rev. 1991, 32, 39-48.

38. Yang, Y. Understanding household switching behavior in the retail electricity market. Energy Policy 2014, 69, 406-414. [CrossRef]

39. Ndebele, T.; Marsh, D.; Scarpa, R. Consumer switching in retail electricity markets: Is price all that matters? Energy Econ. 2019, 83, 88-103. [CrossRef]

40. Lazarsfeld, P. The logical and mathematical foundations of latent structure analysis. In Measurement and Prediction; Stouffer, S.A., Ed.; John Wiley \& Sons: New York, NY, USA, 1950; pp. 362-412.

41. Boxall, P.; Adamowicz, W. Understanding heterogeneous preferences in random utility models: A latent class approach. Environ. Resour. Econ. 2002, 23, 421-446. [CrossRef]

42. Swait, J. A structural equation model of latent segmentation and product choice for cross-sectional revealed preference choice data. J. Retail. Consum. Serv. 1994, 1, 77-89. [CrossRef] 
43. Fonseca, J.R. Customer satisfaction study via a latent segment model. J. Retail. Consum. Serv. 2009, 16, 352-359. [CrossRef]

44. Collins, L.M.; Lanza, S.T. Latent Class and Latent Transition Analysis: With Applications in the Social Behavioral, and Health Sciences; Wiley: Hoboken, NJ, USA, 2010.

45. Walker, J.; Ben-Akiva, M. Generalized random utility model. Math. Soc. Sci. 2002, 43, 303-343. [CrossRef]

46. McFadden, D. The Choice Theory Approach to Market Research. Mark. Sci. 1986, 5, 275-297. [CrossRef]

47. Hagenaars, J.; McCutcheon, A. Applied Latent Class Analysis; Cambridge University Press: Cambridge, UK, 2002.

48. Bolck, A.; Croon, M.; Hagenaars, J. Estimating Latent Structure Models with Categorical Variables: One-Step Versus Three-Step Estimators. Political Anal. 2004, 12, 3-27. [CrossRef]

49. Bandeen-Roche, K.; Miglioretti, D.; Zeger, S.; Rathouz, P. Latent Variable Regression for Multiple Discrete Outcomes. J. Am. Stat. Assoc. 1997, 92, 1375-1386. [CrossRef]

50. Celeux, G.; Soromenho, G. An entropy criterion for assessing the number of clusters in a mixture model. J. Classif. 1996, 13, 195-212. [CrossRef]

51. SORS. SI Stat, Statistical Office of the Republic of Slovenia. 2014. Available online: http://pxweb.stat.si/ pxweb/dialog/statfile2.asp (accessed on 18 April 2020).

52. Zeithaml, V.A.; Berry, L.L.; Parasuraman, A. The Behavioral Consequences of Service Quality. J. Mark. 1996, 60, 31-46. [CrossRef]

53. Fombrun, C.J.; Gardberg, N.A.; Sever, J.M. The Reputation QuotientSM: A multi-stakeholder measure of corporate reputation. J. Brand Manag. 2000, 7, 241-255. [CrossRef]

54. Lichtenstein, D.R.; Ridgway, N.M.; Netemeyer, R.G. Price Perceptions and Consumer Shopping Behaviour: A Field Study. J. Mark. Res. 1993, 30, 234-245. [CrossRef]

55. R Core Team. R: A Language and Environment for Statistical Computing; R Foundation for Statistical Computing: Vienna, Austria, 2016.

56. Linzer, D.A.; Lewis, J.B. poLCA: An R Package for Polytomous Variable Latent Class Analysis. J. Stat. Softw. 2011, 42, 1-29. [CrossRef]

57. Nylund, K.L.; Asparouhov, T.; Muthén, B.O. Deciding on the Number of Classes in Latent Class Analysis and Growth Mixture Modeling: A Monte Carlo Simulation Study. Struct. Equ. Model. 2007, 14, 535-569. [CrossRef]

58. Kotler, P.; Armstrong, G. Principles of Marketing, 17th ed.; Pearson Education Limited: London, UK, 2018.

59. Getzner, M.; Grabner-Kräuter, S. Consumer preferences and marketing strategies for green shares: Specifics of the Austrian market. Int. J. Bank Mark. 2004, 22, 260-278. [CrossRef]

60. Accenture. Engaging the New Energy Consumer, 15 August 2018. Available online: https: $/ /$ www.accenture.com/ \{\}/media/Accenture/Conversion-Assets/DotCom/Documents/Global/PDF/Industries_ 9/Accenture-Utilities-Engaging-Consumers-Acn-Perspective.pdf (accessed on 23 May 2020).

61. Schmidt, J.; Bijmolt, T.H.A. Accurately measuring willingness to pay for consumer goods: A meta-analysis of the hypothetical bias. J. Acad. Mark. Sci. 2020, 48, 499-518. [CrossRef]

62. Sütterlin, B.; Siegrist, M. Public acceptance of renewable energy technologies from an abstract versus concrete perspective and the positive imagery of solar power. Energy Policy 2017, 106, 356-366. [CrossRef]

63. Seebauer, S.; Kulmer, V.; Fruhmann, C. Promoting adoption while avoiding rebound: Integrating disciplinary perspectives on market diffusion and carbon impacts of electric cars and building renovations in Austria. Energy, Sustain. Soc. 2019, 9, 26. [CrossRef]

64. Alberini, A.; Bigano, A.; Boeri, M. Looking for free riding: Energy efficiency incentives and Italian homeowners. Energy Effic. 2014, 7, 571-590. [CrossRef]

65. Achtnicht, M.; Madlener, R. Factors influencing German house owners' preferences on energy retrofits. Energy Policy 2014, 68, 254-263. [CrossRef]

66. Judson, E.P.; Maller, C. Housing renovations and energy efficiency: Insights from homeowners' practices. Build. Res. Inf. 2014, 42, 501-511. [CrossRef]

Publisher's Note: MDPI stays neutral with regard to jurisdictional claims in published maps and institutional affiliations. 